\title{
The Effects of Glucose and Insulin on Renal
}

\section{Electrolyte Transport}

\author{
Ralph A. DeFronzo, Martin Goldberg, and Zalman S. Agus \\ From the Renal Electrolyte Section Department of Medicine, University of \\ Pennsylvania School of Medicine, Hospital of the University of Pennsylvania, \\ and Veteran's Administration Hospital, Philadelphia, Pennsylvania
}

A B S T R A C T The effects of hyperglycemia and hyperinsulinemia on renal handling of sodium, calcium, and phosphate were studied in dogs employing the recollection micropuncture technique. Subthreshold sustained hyperglycemia resulted in an isonatric inhibition of proximal tubular sodium, fluid, calcium, and phosphate reabsorption by $8-14 \%$. Fractional excretion of sodium and phosphate, however, fell $(P<0.01)$ indicating that the increased delivery of these ions was reabsorbed in portions of the nephron distal to the site of puncture and in addition net sodium and phosphate transport was enhanced resulting in a significant antinatriuresis and antiphosphaturia.

The creation of a steady state plateau of hyperinsulinemia while maintaining the blood glucose concentration at euglycemic levels mimicked the effects of hyperglycemia on proximal tubular transport and fractional excretion of sodium and calcium. Tubular fluid to plasma inulin ratio fell, similar to the hyperglycemic studies. These results suggest that the effects of hyperglycemia on renal handling of sodium and calcium may be mediated through changes in plasma insulin concentration. In contrast to hyperglycemia, however, hyperinsulinemia caused a significant fall in tubular fluid to plasma phosphate ratio with enhanced proximal tubular phosphate reabsorption $(P<0.02)$. This occurred concomitantly with a significant inhibition of proximal tubular sodium transport. These data indicate that insulin has a direct effect on proximal tubular phosphate reabsorption, and this effect of insulin is masked by the presence of increased amounts of unreabsorbed glucose in the tubule that ensues when hyperinsulinemia occurs secondary to hyperglycemia. Fractional excretion

Dr. Agus is a Clinical Investigator of the Veteran's Administration.

Presented in part at the National Meeting of American Federation for Clinical Research, Atlantic City, N. J., May 1975.

Received for publication 24 July 1975 and in revised form 26 February 1976. of phosphate fell significantly during insulin infusion but unlike the hyperglycemic studies, the fall in phosphate excretion could be entirely accounted for by enhanced proximal reabsorption.

\section{INTRODUCTION}

Recent clearance studies in man by DeFronzo et al. have shown that hyperinsulinemia is associated with antinatriuresis, antiphosphaturia, and calciuria (1). This effect of insulin on renal electrolyte transport was independent of changes in plasma aldosterone concentration, glomerular filtration rate, renal plasma flow, filtered glucose load, or blood glucose concentration. The data also suggested that the effect of insulin on electrolyte transport occurred in the distal nephron. Similar effects of insulin on sodium transport have been demonstrated in vitro employing amphibian epithelia (2-5) and the isolated perfused dog kidney (6).

A fall in urinary sodium excretion and a calciuria after carbohydrate loading has also been observed by several investigators (7-12). However, whether the changes in sodium and calcium excretion in these studies were secondary to hyperglycemia per se or mediated through changes in plasma insulin concentration was not ascertained. The present study was undertaken to evaluate the separate effects of hyperglycemia and hyperinsulinemia on renal tubular electrolyte transport and to localize these effects within the nephron.

\section{METHODS}

Female mongrel dogs weighing 9-18 kg and fasted for $12 \mathrm{~h}$ were anesthetized with sodium pentobarbital i.v. $(20 \mathrm{mg} / \mathrm{kg})$ and received supplemental doses as required during the experiment. The animals were intubated and ventilated with a Harvard ventilator (Harvard Apparatus Co. Inc., Millis, Mass.). Surgical preparation of the animals for clearance and recollection micropuncture studies was performed as previously described from this laboratory (13). Priming doses of $\left[\mathrm{H}^{3}\right]$ inulin, $100 \mu \mathrm{c} / \mathrm{kg},(14)$, and $\mathrm{PAH},{ }^{1} 4 \mathrm{mg} / \mathrm{kg}$,

${ }^{1}$ Abbreviations used in this paper: FE, fractional excretion; IN, inulin; $\mathrm{P}$, plasma; $\mathrm{PAH}$, para-amino hippurate; $T F$, tubular fluid; UF, ultrafilterable. 
were given followed by sustaining infusions of inulin and PAH in $0.9 \%$ saline at a rate of $0.5 \mathrm{ml} / \mathrm{min}$. Variations of this basic protocol were used in the different groups of animals as described below.

Group I. Time control. To evaluate the effects of the recollection micropuncture technique per se upon the various indices being measured, five dogs received only the maintenance infusion of inulin and $\mathrm{PAH}$ at $0.5 \mathrm{ml} / \mathrm{min}$ for $3-4 \mathrm{~h}$ of the experiment. Initial (control) samples were obtained by micropuncture techniques as previously described (13) from three to eight late surface proximal tubules over 30-60 min. Tubular recollections were begun $40 \mathrm{~min}$ after completion of the initial collections. Urine was collected separately from each kidney during the control and recollection periods and blood samples were drawn via a femoral arterial catheter at the beginning, midpoint, and end of each period.

Group II. Hyperglycemic animals. In $10 \mathrm{dogs,}$ after the initial tubular fluid collections, the arterial plasma glucose concentrations was acutely raised and maintained $70 \mathrm{mg} / \mathrm{dl}$ above the basal level employing the glucose clamp technique (15). A priming infusion of $20 \%$ glucose calculated to raise the plasma glucose concentration $70 \mathrm{mg} / \mathrm{dl}$ was given over $10 \mathrm{~min}$. Plasma glucose concentration was determined every 5-10 min thereafter and a variable infusion of $20 \%$ glucose was adjusted to maintain the glucose concentration at the desired level. After $40 \mathrm{~min}$ of sustained hyperglycemia proximal tubules were repunctured.

The total volume of fluid infused per animal of glucose solution during these studies was $63 \mathrm{ml}$ over a 2-h period. Net fluid balance compared to controls was actually negative, however as the volume of blood drawn to monitor blood glucose in this group averaged $82 \mathrm{ml}$ per animal $/ 2 \mathrm{~h}$ interval. The expansion of the extracellular fluid volume produced by an increase in blood glucose of $70 \mathrm{mg} / \mathrm{dl}$ in a $10-\mathrm{kg}$ dog was estimated at $40 \mathrm{ml}$ representing a net fluid balance of $21 \mathrm{ml}$ per animal in this group as compared to the control group.

Group III. Hyperinsulinemic, euglycemic animals. In seven dogs, after control tubular fluid collections, the arterial plasma insulin concentration was acutely raised by a priming dose of insulin given over $10 \mathrm{~min}$ and this was followed by a sustaining infusion of insulin at a rate of either 1 (three animals), 2 (two animals), or 4 (two animals) $\mathrm{mU} / \mathrm{kg}$ body weight $/ \mathrm{min}$. Concomitantly, an i.v. infusion of $20 \%$ glucose was begun and arterial glucose samples obtained every 5-10 min to allow the adjustment of the glucose infusion rate to maintain each dog's plasma glucose concentration at the preinsulin fasting level (15). Recollections were performed after $40 \mathrm{~min}$ of sustained hyperinsulinemia.

The total volume infused per animal of glucose solution during these studies was $41 \mathrm{ml}$. As $72 \mathrm{ml}$ blood was drawn for estimation of blood glucose, the fluid balance in this group was $-30 \mathrm{ml} /$ animal compared to the controls.

Group IV. Unilateral insulin infusion. In four dogs after the insertion of arterial, venous, and ureteral catheters, the left renal artery was exposed through a midline abdominal incision and a no. 23 gauge scalp vein needle was inserted and kept open with an infusion of $0.9 \%$ saline at the rate of $0.1 \mathrm{ml} / \mathrm{min}$. After three 20 -min control collections, $1.1 \mathrm{mU}$ of insulin/min was given in $0.9 \%$ saline which was infused at a rate of $0.1 \mathrm{ml} / \mathrm{min}$ and $3-530-\mathrm{min}$ urine collections were obtained. Urine was collected separately from each kidney and changes in electrolyte excretion from the left kidney were compared to the right which served as a control.
Analytical methods. Serum and urine sodium, calcium, and phosphate concentrations were determined as previously described (13). $\left[\mathrm{H}^{8}\right]$ inulin activity in tubular fluid, urine, and plasma was determined in a Packard liquid scintillation spectrometer (14) (Packard Instrument Co., Inc., Downers Grove, Ill.).

Tubular fluid concentrations of sodium, calcium, and phosphate were determined by electron microprobe analysis as previously described from this laboratory (16). PAH was measured by Auto-Analyzer (17). (Technicon Instruments Corporation, Ardsley, N. Y.) Blood glucose concentration was determined by the glucose oxidase method with a Beckman Glucose Analyzer (Beckman Instruments, Inc., Cedar Grove, N. J.) and plasma insulin concentration by radioimmunoassay as previously reported (1).

Clearance data, unless otherwise specified, are reported from the micropunctured kidney and were calculated in the usual manner. Fractional reabsorption of electrolytes and fluid in the proximal tubule were calculated by standard formulae (13). For each animal the mean of the micropuncture and clearance observations was calculated and the significance of the mean difference between control and recollection periods for each group was determined by the $t$ test for paired or nonindependent variables. The significance of the difference between control, hyperglycemic, and hyperinsulinemic groups was determined by the $t$ test for unpaired or independent variables (18).

\section{RESULTS}

Group I. Time controls. Glomerular filtration rate and renal plasma flow did not change significantly during the period of study (Table I). Similarly, there were no significant changes in either the serum concentrations of fractional excretion ( $\mathrm{FE}$ ) of sodium and calcium. Initial levels of serum sodium and ultrafilterable calcium were $142 \pm 1.4 \mathrm{meq} / 1$ and $2.87 \pm 0.28 \mathrm{meq} / 1$, respectively (mean $\pm \mathrm{SEM}$ ). The anticipated diurnal increase in $\mathrm{FE}$ of phosphate (19) from $4.55 \pm 0.71$ to $16.49 \pm 1.55 \%$ occurred $(P<0.001)$ and this was associated with a small but significant increase in plasma phosphate concentration from $5.58 \pm 0.37$ to $5.82 \pm 0.37 \mathrm{mg} / \mathrm{dl} \quad(P<0.01)$. Tubular fluid over plasma inulin ratio, $(\mathrm{TF} / \mathrm{P})_{\mathrm{IN}}$, from 27 tubules was $1.57 \pm 0.12$ during the control collections and $1.62 \pm 0.14$ during recollection (Fig. 1) indicating that fractional water and sodium reabsorption by the proximal tubule was not altered by the $3-4 \mathrm{~h}$ experimental procedure. Tubular fluid over ultrafilterable ( $\mathrm{TF} / \mathrm{UF}$ ) phosphate ratio was not measured in these animals, but previous studies from our laboratory indicate that there is no change in proximal tubular phosphate reabsorption with time in control animals despite increased urinary phosphate excretion (13).

Group II. Hyperglycemic animals. After the 12-h overnight fast the plasma glucose concentration averaged $104 \pm 5 \mathrm{mg} / \mathrm{dl}$ and the plasma insulin concentration $6 \pm 1 \mu \mathrm{U} / \mathrm{ml}$. During sustained hyperglycemia the plasma glucose concentration averaged $178 \pm 5 \mathrm{mg} / \mathrm{dl}$ and the plasma insulin concentration $37 \pm 15 \mu \mathrm{U} / \mathrm{ml}$ (Fig. 2). Glucose excretion averaged $1.9 \pm 0.4 \mathrm{~g} / \mathrm{min}$ during the 
TABLE I

Summary of Whole Kidney Clearance Data from the Micropunctured Kidney in Control (Group I), Hyperglycemic (Group II), and Hyperinsulinemic (Group III) Animals

\begin{tabular}{|c|c|c|c|c|c|c|c|c|c|c|}
\hline & \multicolumn{2}{|c|}{$\mathrm{C}_{\text {IN }}$} & \multicolumn{2}{|c|}{$\mathrm{CPAH}_{\mathrm{PA}}$} & \multicolumn{2}{|c|}{$\begin{array}{c}\text { Fractional sodium } \\
\text { excretion }\end{array}$} & \multicolumn{2}{|c|}{$\begin{array}{c}\text { Fractional calcium } \\
\text { excretion }\end{array}$} & \multicolumn{2}{|c|}{$\begin{array}{c}\text { Fractional phosphate } \\
\text { excretion }\end{array}$} \\
\hline & $\mathrm{C}$ & $\mathbf{R}$ & C & $\mathbf{R}$ & C & $\mathbf{R}$ & $\mathrm{C}$ & $\mathbf{R}$ & C & $\mathbf{R}$ \\
\hline & \multicolumn{2}{|c|}{$m l / m i n$} & \multicolumn{2}{|c|}{$m l / m i n$} & \multicolumn{2}{|c|}{$\%$} & \multicolumn{2}{|c|}{$\%$} & \multicolumn{2}{|c|}{$\%$} \\
\hline $\begin{array}{l}\text { I. Controls } \\
(\mathrm{N}=5) \\
\text { Weight }=13.4 \pm 1.9 \mathrm{~kg}\end{array}$ & \multicolumn{2}{|c|}{ NS } & \multicolumn{2}{|c|}{ NS } & \multicolumn{2}{|c|}{ NS } & \multicolumn{2}{|c|}{ NS } & \multicolumn{2}{|c|}{$P<0.001^{*}$} \\
\hline $\begin{array}{l}\text { II. Hyperglycemia } \\
(\mathrm{N}=10) \\
\text { Weight }=9.7 \pm 0.4 \mathrm{~kg}\end{array}$ & \multicolumn{2}{|c|}{ NS } & \multicolumn{2}{|c|}{ NS } & \multicolumn{2}{|c|}{$P<0.01$} & \multicolumn{2}{|c|}{ NS } & \multicolumn{2}{|c|}{$P=0.001$} \\
\hline $\begin{array}{l}\text { III. Hyperinsulinemia } \\
(\mathrm{N}=7) \\
\text { Weight }=9.9 \pm 0.4 \mathrm{~kg}\end{array}$ & \multicolumn{2}{|c|}{ NS } & \multicolumn{2}{|c|}{ NS } & \multicolumn{2}{|c|}{$P=0.001$} & \multicolumn{2}{|c|}{ NS } & \multicolumn{2}{|c|}{$P<0.005$} \\
\hline
\end{tabular}

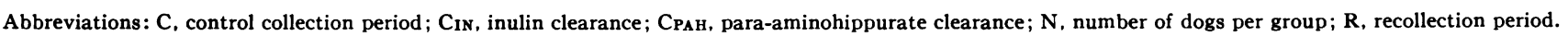

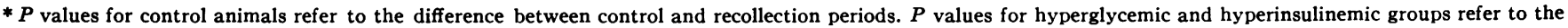
difference in the change (i.e. between control and recollection periods) in each of these groups from the change in control animals.

control period and remained unchanged at $2.0 \pm 0.5 \mu \mathrm{g} /$ min during the hyperglycemic period. Glomerular filtration rate and renal plasma flow were not altered by the glucose infusion (Table I). FE of sodium fell significantly from $0.31 \pm 0.07$ to $0.20 \pm 0.05 \% \quad(P<0.01)$ during recollection and also when the change with time was compared to that observed in the control animals (Table I). Despite a significant rise in plasma phosphate concentration from $6.36 \pm 0.49$ to $7.02 \pm 0.71 \mathrm{mg} / \mathrm{dl} \quad(P<$ $0.05), F E$ of phosphate fell slightly from $9.61 \pm 0.85$ to $7.38 \pm 0.79 \%$ and this change was different from the alteration observed in the control group $(P<0.001$; Fig. 3). Serum UF calcium and FE during the control

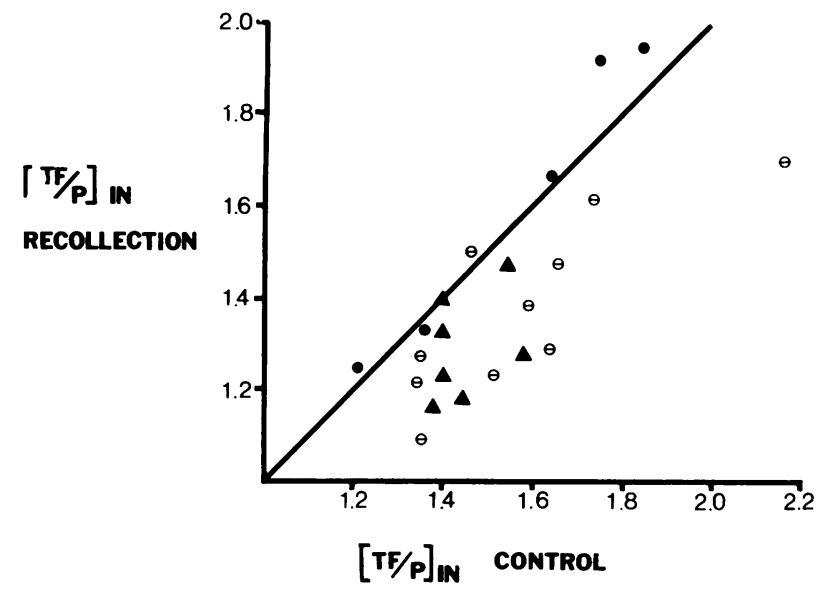

Figure $1(\mathrm{TF} / \mathrm{P})_{\text {In }}$ in control (solid circles), hyperglycemic (open circles), and hyperinsulinemic (solid triangles) dogs. Each point represents the mean of data from 3-5 tubules per dog. The solid line represents the line of identity. collections were $2.92 \pm 0.05 \mathrm{meq} / 1$ and $0.53 \pm 0.12 \%$, respectively, and both remained unchanged after glucose administration.

The micropuncture data are summarized in Figs. 1 and 4 and Table II. A significant fall in $(\mathrm{TF} / \mathrm{P})_{\mathrm{in}}$ from $1.58 \pm 0.08$ to $1.38 \pm 0.06(P<0.005)$ occurred after glucose administration. Since $(T F / U F)_{\text {ca }},(T F / U F)_{\text {po4, }}$ and $(T F / P)_{x=}$ did not change (Table II), the delivery of sodium, calcium, and phosphate out of the proximal tubule increased significantly during hyperglycemia (Fig. 4).

Thus, in this group, hyperglycemia decreased fractional reabsorption of sodium, calcium, phosphate, and fluid by the proximal tubule, yet fractional excretion of sodium and phosphate fell significantly.

Group III. Hyperinsulinemic animals. Fasting plasma glucose and insulin concentrations averaged $111 \pm 7$ $\mathrm{mg} / \mathrm{dl}$ and $9 \pm 3 \mu \mathrm{U} / \mathrm{ml}$, respectively. After the low, middle, and high dose insulin infusions the steady state plasma insulin concentrations averaged 72, 131, and 442 $\mu \mathrm{U} / \mathrm{ml}$. During the period of sustained hyperinsulinemia the plasma glucose concentration averaged $102 \pm 1 \mathrm{mg} / \mathrm{dl}$ (Fig. 2). Since there were no differences in either the micropuncture or clearance data between the three different doses of insulin the data from the seven animals receiving insulin infusion were combined for analysis. Glomerular filtration rate and renal plasma flow were unchanged during the period of insulin infusion (Table I). Similar to the hyperglycemia animals, insulin resulted in a significant fall in FE of sodium and phosphate from $0.34 \pm 0.06$ to $0.17 \pm 0.04 \%$ and $15.99 \pm 1.59$ to $4.65 \pm 0.58 \%$, respectively $(P<0.005$; Table I and Fig. 3 ). Serum sodium and UF phosphate were $145 \pm 0.6$ $\mathrm{meq} / 1$ and $4.82 \pm 0.34 \mathrm{mg} / \mathrm{dl}$ during control collections 


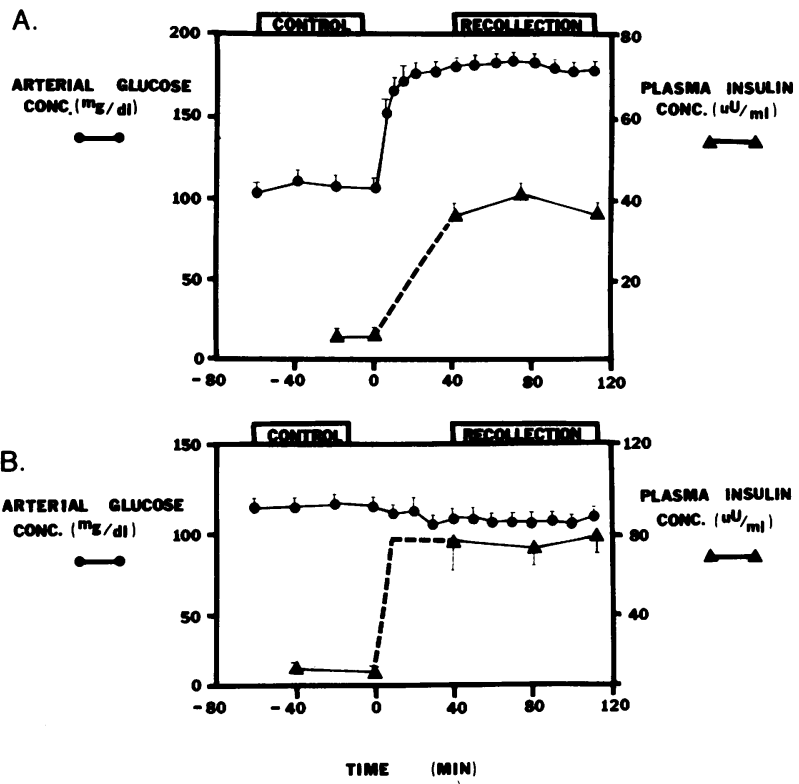

FIGURE 2 Plasma, glucose, and insulin concentrations during (A) hyperglycemic studies and (B) hyperinsulinemic studies. Each point represents the mean \pm SEM.

and were unchanged during insulin administration. Serum UF calcium and FE of calcium were not altered by the insulin infusion. The FE of phosphate fell significantly both within the group and also when compared to controls $(P<0.005)$.

In the proximal tubule $(\mathrm{TF} / \mathrm{P})_{\mathrm{IN}}$ fell from $1.45 \pm 0.02$ to $1.31 \pm 0.04(P<0.02)$; (Table II and Fig. 1 ). TF/P sodium and TF/UF calcium remained unchanged (Table II) and the fractional delivery of both ions out of the proximal tubule increased (Fig. 4). In contrast to the hyperglycemic animals, however, (TF/UF) Po4 fell from $0.72 \pm 0.09$ to $0.52 \pm 0.07(P<0.005)$ and proximal tubular phosphate reabsorption increased from $47 \pm 6$ to $61 \pm 5 \%(P<0.02)$ of filtered load thereby decreasing delivery out of the proximal tubule (Fig. 4).

Thus, in this group, hyperinsulinemia decreased fractional reabsorption of sodium, calcium, and fluid by the

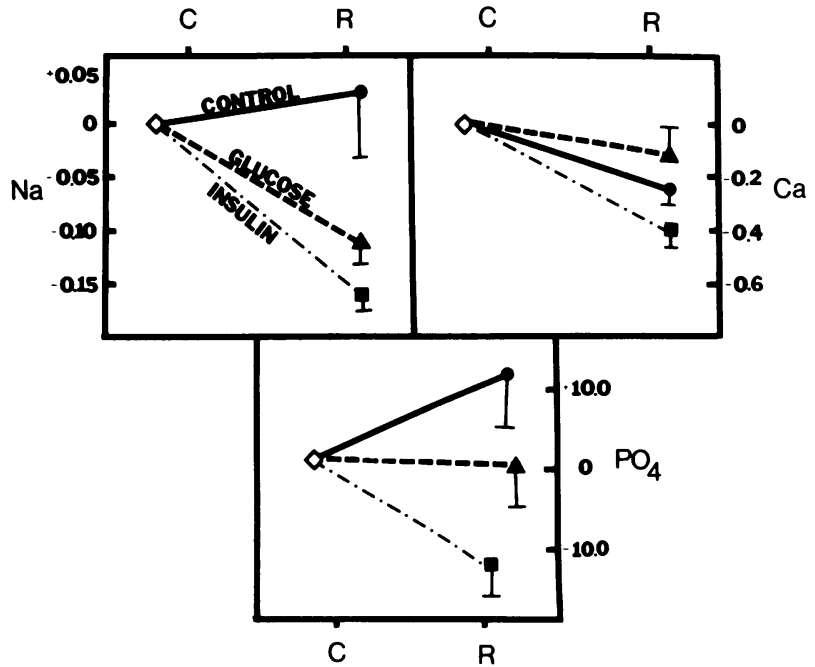

Figure 3 Mean change in fractional excretion of sodium, calcium, and phosphate during recollection ( $R$ ) from baseline $(C)$ in control (solid circles), hyperglycemic (solid triangles), and hyperinsulinemic (solid squares) groups. Each point represents the mean \pm SEM for each group.

proximal tubule, yet fractional sodium excretion fell significantly similar to glucose. In contrast to hyperglycemia, however, proximal tubular phosphate reabsorption was markedly enhanced and $\mathrm{FE}$ of phosphate fell.

Group IV. Unilateral renal artery insulin infusion. Table III summarizes the percent change in fractional reabsorption of sodium in four dogs in which insulin was infused into the left renal artery. Data are shown for both right and left kidneys. In the insulin infused kidney, percent fractional sodium excretion decreased by a mean value of $50 \pm 13 \%$ which was significantly different from the uninfused kidney $(P<0.005)$. Percent fractional phosphate excretion rose in the uninfused kidney from $11.42 \pm 3.72$ to $17.14 \pm 2.45 \%(P<0.05)$ while there was no change in phosphate excretion in the insulin infused kidney (from $10.9 \pm 3.46$ to $11.93 \pm 3.16 \%$ ).

TABLE II

Summary of Micropuncture Data in Hyperglycemic (Group II) and Hyperinsulinemic (Group III) Animals

\begin{tabular}{|c|c|c|c|c|c|c|c|c|}
\hline & \multicolumn{2}{|c|}{$(\mathrm{TF} / \mathrm{P}) \mathrm{IN}$} & \multicolumn{2}{|c|}{$(\mathrm{TF} / \mathrm{P}) \mathrm{Na}$} & \multicolumn{2}{|c|}{$(\mathrm{TF} / \mathrm{UF}) \mathrm{Ca}$} & \multicolumn{2}{|c|}{ (TF/UF)PO } \\
\hline & C & $\mathbf{R}$ & c & $\mathbf{R}$ & c & $\mathbf{R}$ & c & $\mathbf{R}$ \\
\hline $\begin{array}{l}\text { Hyperglycemia } \\
(\mathrm{N}=10, \mathrm{n}=50)\end{array}$ & \multicolumn{2}{|c|}{$\begin{array}{c}1.58 \pm 0.08 \quad 1.38 \pm 0.06 \\
P<0.005^{*}\end{array}$} & \multicolumn{2}{|c|}{ NS } & \multicolumn{2}{|c|}{ NS } & \multicolumn{2}{|c|}{${ }_{\text {NS }}^{0.65 \pm 0.07}$} \\
\hline $\begin{array}{l}\text { Hyperinsulinemia } \\
(\mathrm{N}=7, \mathrm{n}=35)\end{array}$ & $\begin{array}{r}1.45 \pm 0.02 \\
P=\end{array}$ & $\begin{array}{l}1.31 \pm 0.04 \\
.02 *\end{array}$ & $0.99 \pm 0.01$ & $1.00 \pm 0.01$ & $1.05 \pm 0.05$ & $1.09 \pm 0.03$ & $\begin{array}{r}0.72 \pm 0.09 \\
P<\end{array}$ & $\begin{array}{l}0.52 \pm 0.07 \\
.005^{*}\end{array}$ \\
\hline
\end{tabular}

Abbreviations: $\mathrm{C}$, control collection period; IN, inulin; $\mathbf{n}$, total number of tubules; $\mathbf{N}$, number of dogs per group; $\mathbf{R}$, recollection period; and $\mathbf{T F} / \mathbf{P}$ and TF/UF, ratio of tubular fluid to plasma and ultrafiltrate respectively.

* $P$ values refer to differences between control and recollection periods 


\section{DISCUSSION}

It is clear that insulin and glucose have significant effects on renal tubular electrolyte transport and that these effects are exerted both proximally and distally. Sustained, subthreshold hyperglycemia results in a significant reduction in urinary sodium excretion despite enhanced delivery out of the proximal tubule. Our data in the proximal tubule are different than those obtained with microperfusion studies. Thus, previous studies by Kokko in the isolated rabbit proximal convoluted tubule (20) and by Weinman et al. using microperfusion techniques in the rat (21), indicate that base-line sodium transport is diminished when glucose is removed from the perfusate. Our studies however utilizing sustained systemic hyperglycemia obviously differ markedly in design and the mechanism of these effects is not readily apparent. Proximal tubular sodium reabsorption was inhibited without a change in $T F / P$ sodium ratio indicating an isonatric inhibition of proximal tubular fluid and sodium transport after glucose administration. This effect is unlike that of mannitol and similar osmotic diuretics which are associated with a fall in $T F / P$ sodium secondary to primary inhibition of fluid reabsorption (22). Thus, it seems likely that the effects of subthreshold hyperglycemia are related to either systemic or intrarenal metabolic alterations. Since hyperglycemia in our studies was associated with a rise in plasma insulin concentration (range $=16-71 \mu \mathrm{U} / \mathrm{ml}$ ), it was not clear whether the observed changes in renal electrolyte transport were related to the hyperglycemia and increased filtered load of glucose or were due to the effect of insulin. To answer this question, we per-

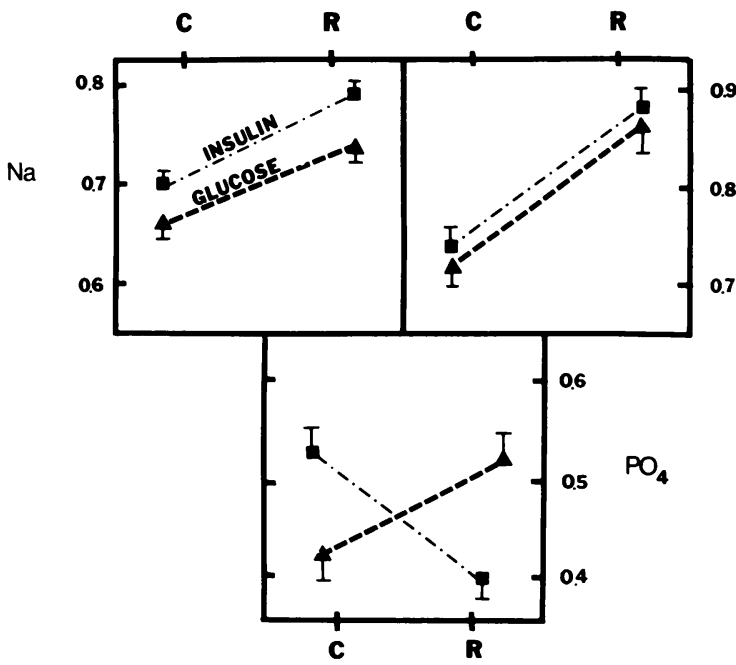

$\mathrm{Ca}$

FIgURE 4 Proximal tubular fractional rejection of sodium, calcium, and phosphate in hyperglycemic (solid triangles) and hyperinsulinemic (solid squares) animals. Each point represents the mean $\pm S E M$ of the data obtained during control (C) and recollection periods (R).
TABLE III

Percent Change in Fractional Excretion of Sodium after Insulin Infusion Directly into the Left Renal Artery. The Right Kidney Serves as the Time Control

\begin{tabular}{ccc}
\hline Left & Right \\
\hline$\%$ & $\%$ \\
-30 & +11 \\
-59 & -26 \\
-83 & -45 \\
-27 & +14 \\
\hline \multicolumn{2}{c}{$P<0.005$} \\
\hline
\end{tabular}

formed studies during a steady state plateau of hyperinsulinemia while maintaining euglycemia. Similar to glucose infusion, hyperinsulinemia resulted in a fall in FE of sodium. Proximal fluid reabsorption was similarly reduced and proximal tubular sodium reabsorption was also inhibited without a change in $T F / P$ sodium, again indicating proportional inhibition of fluid and sodium transport. These data suggest that insulin also has an effect on sodium reabsorption distal to the site of proximal puncture. The similarity between the effects of hyperinsulinemia and hyperglycemia on sodium transport in both segments of the nephron suggests that the effects of glucose may be mediated via insulin. Furthermore, the effects of insulin (range of plasma insulin concentration with low dose infusion $=49-89 \mu \mathrm{U} / \mathrm{ml}$ ) on renal sodium transport were observed at levels within the physiologic range and were comparable to those observed during the hyperglycemic studies. The demonstration of a significant unilateral fall in urinary sodium excretion after insulin infusion directly into one renal artery is consistent with a direct renal effect of insulin on sodium transport and is in agreement with data obtained with insulin in the isolated, perfused kidney preparation (6). The localization of the antinatriuretic effect of insulin to portions of the nephron distal to the site of proximal puncture in these micropuncture studies is in agreement with free water clearance studies previously reported in man (1). Insulin has also been shown to stimulate sodium transport by the urinary toad bladder, a preparation used to simulate the distal nephron (2-5).

The infusion of both glucose and insulin were associated with a significant inhibition of proximal tubular calcium transport but this was not apparent in the final urine. Thus, the increased calcium load must have been reabsorbed beyond the site of proximal puncture. An antinatriuresis and a dissociation between sodium and calcium transport associated with increased calcium 
excretion has been reported after glucose loading in humans $(7,8)$. This difference may reflect species variation, the use of anesthesia in our studies, or may be related to the route of glucose administration. It should also be pointed out, however, that in contrast to our studies, glucosuria was present in the human studies and this may contribute to observed differences.

Our data also demonstrate that both insulin and glucose reduce phosphate excretion. Prior studies in man (23-25) and dog (26-28) had suggested that hyperglycemia increases renal phosphate excretion. In contrast to our studies, however, significant glucosuria was present in all of these previous studies. Furthermore, in the dog studies (26-28) hyperphosphatemia was produced by phosphate infusion before glucose administration. Thus, an enhancing effect of hyperglycemia on phosphate reabsorption may have been masked by an osmotic effect of glucose or prior phosphate administration. The fall in phosphate excretion after glucose administration in our studies is even more impressive when compared to the diurnal increase in FE of phosphate noted in the control animals.

Proximal tubular phosphate reabsorption after glucose was inhibited concomitantly with fluid and sodium. Yet fractional phosphate excretion fell indicating that enhanced reabsorption of phosphate distal to the site of proximal micropuncture was responsible for the reduction in phosphate excretion. Since previous micropuncture studies in the rat by Amiel et al. (29) and Agus et al. (30) have shown that the major fraction of distal phosphate reabsorption occurs beyond the loop of Henle, it is likely that a significant portion of the proximally rejected phosphate in our studies was reabsorbed in the late distal tubule and/or collecting duct.

The decrease in FE of phosphate with insulin was even more striking than that after glucose and was observed in the absence of a change in filtered phosphate load. This effect of insulin on phosphate excretion is similar to that previously reported in man (1). Several other studies have documented a decrease in phosphate clearance after insulin administration $(24,31,32)$ but a concomitant fall in plasma phosphate concentration also occurred.

Proximal tubular phosphate reabsorption was increased by insulin despite simultaneous inhibition of sodium reabsorption. Although Wen has previously shown that proximal TF/UF phosphate can be increased or decreased without a change in $\mathrm{TF} / \mathrm{P}$ inulin (33), our observations appear to be the first demonstration that proximal tubular sodium and phosphate transport can vary in opposite directions simultaneously, and suggests for the first time the presence of sodium independent phosphate transport in the proximal tubule. The increase in proximal phosphate reabsorption after insulin is in contrast to the decreased reabsorption seen with glucose. It seems likely that when hyperinsulinemia occurs in association with hyperglycemia and an increase in the filtered load of glucose, the stimulation of phosphate transport by insulin is masked by the presence of increased amounts of unreabsorbed glucose in the tubule. Several investigators have previously postulated that glucose and phosphate may share a common transport pathway and that they may compete for transport sites within this pathway (34). Our results are compatible with such a proximal competitive inhibition of glucose on phosphate transport, although the cellular loci and nature of such a system remain to be delineated.

The mechanism of the stimulation of phosphate transport by insulin in our studies is not clear. Since serum phosphate and glomerular filtration rate remained constant after insulin, alterations in the filtered phosphate load cannot explain the changes in renal tubular phosphate transport. Recent studies by Shah et al. (35) indicate that hypoglycemia may stimulate the secretion of parathyroid hormone. If the inverse is also true, such that hyperglycemia (or increased cellular glucose transport with hyperinsulinemia) inhibited parathyroid hormone excretion, then it is possible that decreased levels of parathyroid hormone may have played a role in the enhanced phosphate reabsorption observed with insulin in these studies. This would not explain the alterations in sodium transport as parathyroid hormone has previously been shown to inhibit proximal tubular fluid reabsorption. In addition, the data obtained with intrarenal infusion of insulin indicate that at least part of the antiphosphaturia may be related to a direct renal effect. In this regard, it is of interest that insulin has been shown to reduce adipose tissue and liver cyclic AMP levels, either through depression of adenylate cyclase activity or enhanced phosphodiesterase activity (36). Similar effects of insulin in renal tubular cells could explain some of the effects observed in our studies.

In summary, glucose has dual effects in the nephron. Proximally, it results in an isonatric inhibition of fluid and sodium transport along with calcium and phosphate. The increased load of these ions delivered from the proximal tubule is reabsorbed distal to the puncture site. In addition there is an enhanced net reabsorption of sodium and phosphate. Insulin simulates the effects of glucose on sodium and calcium in both the proximal tubule and in portions of the nephron distal to the site of puncture. In contrast to glucose, however, insulin dissociates sodium and phosphate reabsorption and strikingly enhances proximal tubular phosphate reabsorption contributing to the marked reduction in phosphate excretion. Although the decreased phosphate excretion after insulin administration can entirely be accounted for by increased proximal tubular reabsorption, the re- 
sults of the hyperglycemic studies suggest that insulin may also enhance phosphate transport at sites distal to the site of proximal puncture.

\section{ACKNOWLEDGMENTS}

This work was supported by a research grant from the National Heart and Lung Institute, HL-00340, the Veteran's Administration, and by a training grant from the National Institute of Arthritis, Metabolic, and Digestive Diseases, AM-05634. We should like to thank Dorothy Senesky, Susan Canning, Mattie Davis, Marguerite LaPorta, Francis McKee, Sandra Markus, Terry Liebsch, Carmen D'Angelo, Phyllis May, Marva Lee, and Freda Rappaport for technical assistance in performing the studies and for the laboratory analyses. Drs. Reubin Andres and Jordan Tobin kindly performed the insulin determinations.

\section{REFERENCES}

1. DeFronzo, R. A., C. R. Cooke, R. Andres, G. R. Faloona, and P. J. Davis. 1975. The effect of insulin on renal handling of sodium, potassium, calcium, and phosphate in man. J. Clin. Invest. 55: 845-855.

2. Herrera, F. C., G. Whittembury, and A. Planchart. 1963. Effect of insulin on short-circuit current across isolated frog skin in the presence of calcium and magnesium. Biochim. Biophys. Acta. 66: 170-172.

3. André, R., and J. Crabbé. 1966. Stimulation by insulin of active sodium transport by toadskin: influence of aldosterone and vasopressin. Arch. Int. Physiol. Biochim. 74: 538-540.

4. Crabbé, J., and B. François. 1967. Stimulation par l'insuline du transport actif de sodium à travers les membranes épithéliales du crapaud, Bufo marinus. Ann. Endocrinol. 28: 713-715.

5. François, B., M. de Gasparo, and J. Crabbé. 1969. Interaction between isolated amphibian skin and insulin. Arch. Int. Physiol. Biochim. 77: 527-530.

6. Nizet, A., P. Lefebvre, and J. Crabbé. 1971. Control by insulin of sodium, potassium, and water excretion by the isolated dog kidney. Pfluegers Arch. Eur. J. Physiol. 323: 11-20.

7. Lennon, E. J., and W. F. Piering. 1970. A comparison of the effects of glucose ingestion and $\mathrm{NH}_{4} \mathrm{Cl}$ acidosis on urinary calcium and magnesium excretion in man. J. Clin. Invest. 49: 1458-1465.

8. Lennon, E. J., J. Lemann, Jr., W. F. Piering, and L. S. Larson. 1974. The effect of glucose on urinary cation excretion during chronic extracellular volume expansion in normal man. J. Clin. Invest. 53: 1424-1433.

9. Lindeman, R. D., S. Adler, M. J. Yiengst, and E. S. Beard. 1967. Influence of various nutrients on urinary divalent cation excretion. J. Lab. Clin. Med. 70: 236-245.

10. Lindeman, R. D., S. Adler, M. J. Yiengst, and E. S. Beard. 1970. Natriuresis and carbohydrate-induced antinatriuresis after overnight fast and hydration. Nephron. 7: 289-300.

11. Garnett, E. S., and C. Nahmias. 1974. The effect of glucose on the urinary excretion of sodium and hydrogen ion in man. Clin. Sci. Mol. Med. 47: 589-598.

12. Hodgkinson, A., and F. W. Heaton. 1965. The effect of food ingestion on the urinary excretion of calcium and magnesium. Clin. Chim. Acta 11: 354-362.
13. Agus, Z. S., J. B. Puschett, D. Senesky, and M. Goldberg. 1971. Mode of action of parathyroid hormone and cyclic adenosine $3^{\prime}, 5^{\prime}$-monophosphate on renal tubular phosphate reabsorption in the dog. J. Clin. Invest. 50: 617-626.

14. Staum, B. B., R. J. Hamburger, and M. Goldberg. 1972. Tracer microinjection of the study of renal tubular phosphate reabsorption in the rat. J. Clin. Invest. 51: 2271-2276.

15. Sherwin, R. S., K. J. Kramer, J. D. Tobin, P. A. Insel, J. E. Liljenquist, M. Berman, and R. Andres. 1974. A model of the kinetics of insulin in man. J. Clin. Invest. 53: 1481-1492.

16. Agus, Z. S., L. B. Gardner, L. H. Beck, and M. Goldberg. 1973. Effects of parathyroid hormone on renal tubular reabsorption of calcium, sodium and phosphate. Am. J. Physiol. 224: 1143-1148.

17. Brun, C. 1951. A rapid method for the determination of para-aminohippuric acid in kidney function tests. $J$. Lab. Clin. Med. 37: 955-958.

18. Croxton, F. E. 1959. Elementary statistics with applications in medicine and the biological sciences. Dover Publications Inc., New York. 235-240.

19. Hartenbower, D. L., R. M. Friedler, J. W. Coburn, and S. G. Massry. 1973. Spontaneous variations in electrolyte excretion in the dog. Clin. Res. 21:283. (Abstr.)

20. Kokko, J. P. 1973. Proximal tubular potential difference. Dependence on glucose, $\mathrm{HCO}_{3}{ }^{-}$and amino acids. $J$. Clin. Invest. 52: 1362-1367.

21. Weinman, E. J., W. N. Suki, and G. Eknoyan. 1975. Effect of $d$-glucose on the reabsorption of water in the proximal tubule of the rat. Kidney Int. 8: 493. (Abstr.)

22. Seely, J. F., and J. H. Dirks. 1969. Micropuncture study of hypertonic mannitol diuresis in the proximal and distal tubule of the dog kidney. J. Clin. Invest. 48: 2330-2340.

23. Levitan, B. A. 1951. Effect in normal man of hyperglycemia and glycosuria on excretion and reabsorption of phosphate. J. Appl. Physiol. 4: 224-226.

24. Huffman, E. R., C. J. Hlad, Jr., N. E. Whipple, and H. Elrick. 1958. The influence of blood glucose on the renal clearance of phosphate. J. Clin. Invest. 37: 369379.

25. Fox, M., S. Thier, L. Rosenberg, and S. Segal. 1964. Impaired renal tubular function induced by sugar infusion in man. J. Clin. Endocrinol. Metab. 24: 1318-1327.

26. Ginsburg, J. M. 1972. Effect of glucose and free fatty acid on phosphate transport in dog kidney. Am.J. Physiol. 222: 1153-1160.

27. Pitts, R. F., and R. S. Alexander. 1944. The renal reabsorptive mechanism for inorganic phosphate in normal and acidotic dogs. Am. J. Physiol. 142: 648-662.

28. Cohen, J. J., F. Berglund, and W. D. Lotspeich. 1957. Interactions during renal tubular reabsorption in the dog among several anions showing a sensitivity to glucose and phlorizin. Am. J. Physiol. 189: 331-338.

29. Amiel, C., H. Kuntziger, and G. Richet. 1970. Micropuncture study of handling of phosphate by proximal and distal nephron in normal and parathyroidectomized rat. Evidence for distal reabsorption. Pfiuegers Archiv. Gesamte Physiol. Menschen Tiere. 317: 93-109.

30. Agus, Z. S., L. H. Beck, S. Goldfarb, P. J. S. Chiu, D. Senesky, and M. Goldberg. 1976. Renal tubular sites and mode of phosphate transport: the effects of volume expansion and parathyroid hormone. Fed. Proc. In press.

31. Sohkey, S. S., and F. N. Allan. 1924. The relationship 
of phosphates to carbohydrate metabolism. I. Time relationship of the changes in phosphate excretion caused by insulin and sugar. Biochem. J. 18: 1170-1184.

32. Eggleton, M. G., and S. Shuster. 1954. Glucose and phosphate excretion in the cat. J. Physiol. 124: 613-622.

33. Wen, S. F. 1974. Micropuncture studies of phosphate transport in the proximal tubule of the dog. The relationship to sodium reabsorption. J. Clin. Invest. 53: 143-153.

34. Harter, H. R., A. Mercado, W. E. Rutherford, H.
Rodriguez, E. Slatopolsky, and S. Klahr. 1974. Effects of phosphate depletion and parathyroid hormone on renal glucose reabsorption. Am. J. Physiol. 227: 1422-1427.

35. Shah, J. H., G. S. Motto, S. C. Kukreja, G. K. Hargis, and Gerald A. Williams. 1975. Stimulation of the secretion of parathyroid hormone during hypoglycemic stress. J. Clin. Endocrinol. Metab. 41: 692-696.

36. Appleman, M. M., W. J. Thompson, and T. R. Russell. 1973. Cyclic nucleotide phosphodiesterases. Adv. Cyclic Nucleotide Res. 3 : 65-98. 